\title{
A New Perspective on the Advanced Microblade Cutting Method for Reliable Adhesion Measurement of Composite Electrodes
}

\author{
Jihun Song ${ }^{1 \dagger}$, Dong Ok Shin ${ }^{2 \dagger}$, Seoungwoo Byun ${ }^{1}$, Youngjoon Roh ${ }^{1}$, Cheol Bak ${ }^{1}$, \\ Juhye Song ${ }^{2}$, Jaecheol Choi ${ }^{2}$, Hongkyung Lee ${ }^{1,4}$, Tae-Soon Kwon ${ }^{5}$, Young-Gi Lee ${ }^{2 *}$, \\ Myung-Hyun Ryou ${ }^{3 *}$, and Yong Min Lee ${ }^{1,4 *}$ \\ ${ }^{1}$ Department of Energy Science and Engineering, Daegu Gyeongbuk Institute of Science and Technology (DGIST), 333 \\ Techno Jungang-daero, Hyeonpung-eup, Dalseong-gun, Daegu 42988, Republic of Korea \\ ${ }^{2}$ Intelligent Sensors Research Section, Electronics and Telecommunications Research Institute (ETRI), 218 Gajeong-ro, \\ Yuseong-gu, Daejeon 34129, Republic of Korea \\ ${ }^{3}$ Department of Chemical and Biological Engineering, Hanbat National University, 125 Dongseo-daero, Yuseong-gu, Dae- \\ jeon 34158, Republic of Korea \\ ${ }^{4}$ Energy Science and Engineering Research Center, Daegu Gyeongbuk Institute of Science and Technology (DGIST), 333 \\ Techno Jungang-daero, Hyeonpung-eup, Dalseong-gun, Daegu 42988, Republic of Korea \\ ${ }^{5}$ Railroad Safety Research Division, Korea Rairoad Research Institute (KRRI), 176, Cheoldobangmulgwan-ro, Uiwang-si, \\ Gyeonggi-do 16105, Republicn of Korea
}

\begin{abstract}
The microblade cutting method, so-called SAICAS, is widely used to quantify the adhesion of battery composite electrodes at different depths. However, as the electrode thickness or loading increases, the reliability of adhesion values measured by the conventional method is being called into question more frequently. Thus, herein, a few underestimated parameters, such as friction, deformation energy, side-area effect, and actual peeing area, are carefully revisited with ultrathick composite electrodes of $\left.135 \mu \mathrm{m}(6 \mathrm{mAh} \mathrm{cm})^{-2}\right)$. Among them, the existence of side areas and the change in actual peeling area are found to have a significant influence on measured horizontal forces. Thus, especially for ultrahigh electrodes, we can devise a new SAICAS measurement standard: 1) the side-area should be precut and 2) the same actual peeling area must be secured for obtaining reliable adhesion at different depths. This guideline will practically help design more robust composite electrodes for high-energy-density batteries.
\end{abstract}

Keywords : Advanced Microblade Cutting Method, Adhesion, Ultrathick Composite Electrode, Side-Area Effect, Actual Peeling Area

Received : 6 October 2021, Accepted: 25 October 2021

\section{Introduction}

The mechanical robustness of composite electrodes in various energy storage and conversion devices is as important as the high theoretical capacity of active materials because physical delamination of the electrode coating layer from the current collec-

$\dagger$ These authors contributed equally to this work.

*E-mail address: yongmin.lee@dgist.ac.kr (Y.M. Lee), mhryou@hanbat.ac.kr (M. Ryou), lyg@etri.re.kr (Y. Lee)

DOI: https://doi.org/10.33961/jecst.2021.00976

This is an open-access article distributed under the terms of the Creative Commons Attribution Non-Commercial License (http://creativecommons.org/licenses/by-nc/4.0) which permits unrestricted non-commercial use, distribution, and reproduction in an medium, provided the original work is properly cited. tor may lead to the rapid fading of capacity or even the death of the battery, even though the active materials of the electrode are still alive. In fact, reports of these types of structural collapse in composite electrodes have become more frequent as electrode designs become increasingly complex to meet the stringent requirements on energy density. More specifically, lower binder content and higher electrode loading level imply that the deterioration of mechanical robustness of composite electrodes is avoidable. To solve this problem, previous studies have focused on new binder materials with higher adhesive/cohesive strength, lower cost, higher flexibility and improved processability [1-8]. Moreover, the limited 
amount of binder used in commercial battery cells, such as lithium-ion batteries (LIBs), to control their distribution and properties within the electrode, has received increased attention from a practical point of view [9-11]. For instance, drying conditions or posthigh-temperature annealing significantly affect the distribution and properties of binders. Thus, analyzing the properties of composite electrodes is of great importance to ensure the reliability of high-energydensity batteries.

For this purpose, quantitative analysis instruments have been developed, such as X-ray photoelectron spectroscopy, X-ray fluorescence, electron probe microanalysis, secondary ion mass spectrometry, laser-induced breakdown spectroscopy (LIBS), and laser-ablation inductively coupled plasma mass spectrometry (LA-ICP-MS). Although each instrument has its own advantages and disadvantages, all are capable of analyzing the binder distribution in composite electrodes. The application of LA-ICP-MS has rapidly increased because it can precisely quantify the material content as a function of depth, while ablating the electrode with the help of a high-intensity pulse laser [12-23]. However, the aforementioned instruments are unable to reveal the original adhesive or cohesive properties of binders, which are influenced not only by their content but also their microstructure, such as crystallinity and crystalline size. Therefore, in a real electrode production line, the drying conditions or post-high-temperature annealing is carefully controlled. To overcome this limitation, a microblade cutting method was devised as a Hesiometer by W.K. Asbeck in 1962 [24], and commercially developed as a surface and interfacial cutting analysis system (SAICAS, Daipla Wintes, Japan) in 1991 [25], to control or measure the horizontal and vertical forces of a microblade with a width of 1-2 mm during cutting and peeling of composite electrodes. In particular, the horizontal forces are easily converted into shear strength and adhesive/ cohesive strength through simple geometric manipulations during cutting and peeling, respectively. Using these advantages of SAICAS, we have reported on the successful measurement of adhesion and cohesion of various composite electrodes for LIBs since 2014 [26-47]. More specifically, the effects of binder type, content, distribution, and microstructure on adhesion and cohesion have been systematically investigated using a variety of elec- trode samples. In 2020, the actual adhesion and cohesion of LIB composite electrodes impregnated in a liquid electrolyte were measured using a specially designed sample holder [45]. However, despite the convenience of SAICAS, doubts still remain over its ability to interpret measured forces as adhesion or cohesion because there are other factors that affect the measured force values.

Here, we investigate the correlation between the peel force measured by SAICAS and the corresponding adhesion or cohesion value with a highly loaded LIB LiNi ${ }_{0.6} \mathrm{Mn}_{0.2} \mathrm{Co}_{0.2} \mathrm{O}_{2}$ (NMC622) cathode. In particular, overlooked parameters, such as two types of friction values on the front and side of the blade, additional force to cut the side-area of the sample, and increased actual peeling area at higher cutting depths, were systematically analyzed by preparing a variety of control samples.

\section{Materials and Methods}

\subsection{Fabrication of composite electrodes}

For the SAICAS measurements, a composite electrode consisting of $93 \mathrm{wt} \% \mathrm{LiNi}_{0.6} \mathrm{Mn}_{0.2} \mathrm{Co}_{0.2} \mathrm{O}_{2}$ (NCM622, L\&F Korea), $3 \mathrm{wt} \%$ polyvinylidene fluoride (PVdF, KF-1300, Mw 350k, Kureha, Japan) binder, and $4 \mathrm{wt} \%$ conducting carbon (Super P Li, Imerys, Belgium) was coated on an Al current collector $(15 \mu \mathrm{m}$, Sam-A Aluminum, Korea). After drying at $160^{\circ} \mathrm{C}$ for $1 \mathrm{~h}$, the composite electrode was rollpressed to obtain a thickness of $135 \mu \mathrm{m}$ and a density of $2.65 \mathrm{~g} \mathrm{~cm}^{-3}$.

\subsection{Binder distribution analysis of the composite electrode}

To confirm the PVdF binder distribution in the composite electrode, the relative fluorine ratios at specific depths were analyzed using LIBS (Applied Spectra, Inc., J200 LIBS) (Fig. S1). This experiment was repeated at different 25 points to ensure its accuracy.

\subsection{Physical analysis of pristine and peeled com- posite electrodes}

To confirm the reliability of the SAICAS measurements, the actual depth of cut was evaluated using a confocal optical microscope (HYBRID Color Laser Confocal Microscope, Laser Tec) and scanning electron microscopy (SEM, FE-SEM, SU8020, Hitachi, 
Japan). The depth as well as the surface and side uniformity were analyzed (Fig. S2).

\subsection{Development of von Misses stress model}

We developed a stress evaluation model to simulate the distribution of stress on the blade before and after side-cutting using COMSOL Multiphysics 5.5. The conditions of the SAICAS measurements, in which the blade moved $2 \mu \mathrm{m} \mathrm{s}^{-1}$ horizontally with no movement in the vertical direction, as shown in Scheme 1C-D, were applied to this model. The model assumed that the stress during cutting and the area subjected to the force were constant.

\section{Results and Discussion}

\subsection{Adhesion measurement using SAICAS}

SAICAS measures the adhesion by cutting a filmtype sample with different types of microblades. First, the composite electrode was cut vertically and horizontally until the target depth was reached (regions $\mathrm{i}$ and ii in Scheme 1A). Then, the adhesion was measured by cutting a sample horizontally (regions ii and iii in Scheme 1A). Scheme 1B-D show the schematics of snapshots at measurement moments of i, ii and iii in Scheme 1A. The Video 1 shows that SAICAS measures adhesion in real time. The principle of the SAICAS measurement is described in Fig. S3.

\subsection{Limitations in adhesion measurement based on the conventional method}

In general, the adhesion of the composite electrodes was measured by peeling the electrode at a specific thickness from the surface without any pretreatment. When the standard composite electrode with 93 wt\% NCM622 and $135 \mu \mathrm{m}$ thickness was analyzed using the conventional method, its average adhesion at depths of $20 \mu \mathrm{m}, 40 \mu \mathrm{m}, 60 \mu \mathrm{m}$, and $80 \mu \mathrm{m}$ were $0.0681 \mathrm{kN} \mathrm{m}^{-1}, 0.1039 \mathrm{kN} \mathrm{m}^{-1}$, $0.1482 \mathrm{kN} \mathrm{m}^{-1}$, and $0.2406 \mathrm{kN} \mathrm{m}^{-1}$, respectively. Furthermore, the adhesion profiles measured four times
A

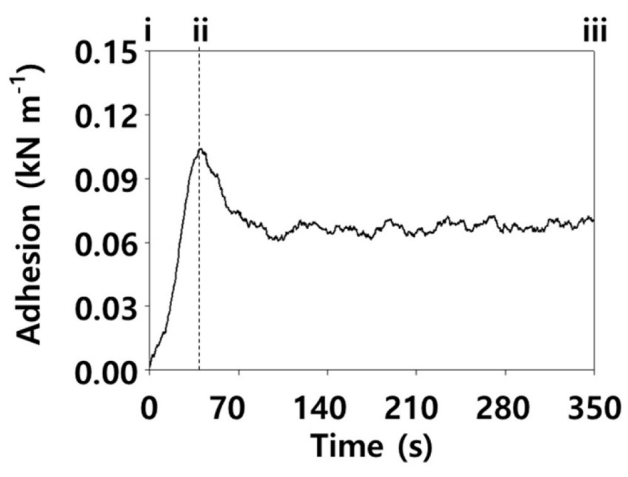

C

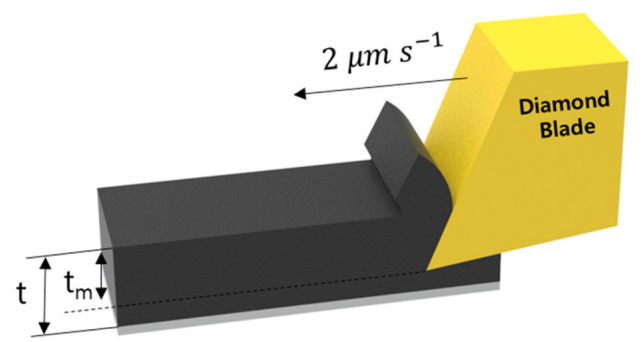

B

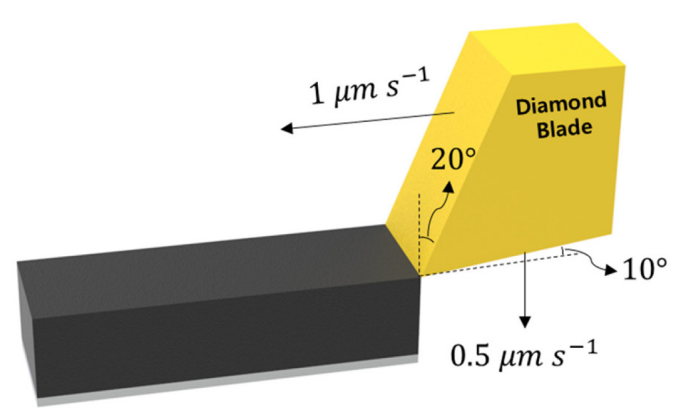

D

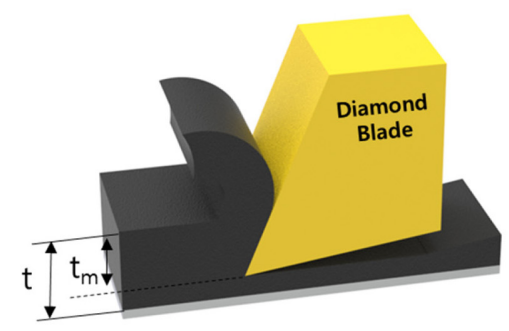

Scheme 1. A) Representative adhesion and time profile during SAICAS measurement; B)-D) the schematics of the status of microblade and composite electrode at points i, ii, and iii assigned in A). Points i, ii, and iii correspond to the moments of initial measurement, when the target depth was reached, and the end of measurement, respectively. 
A

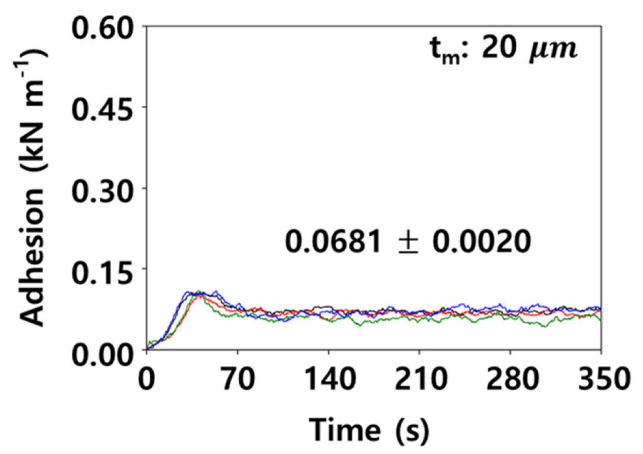

C

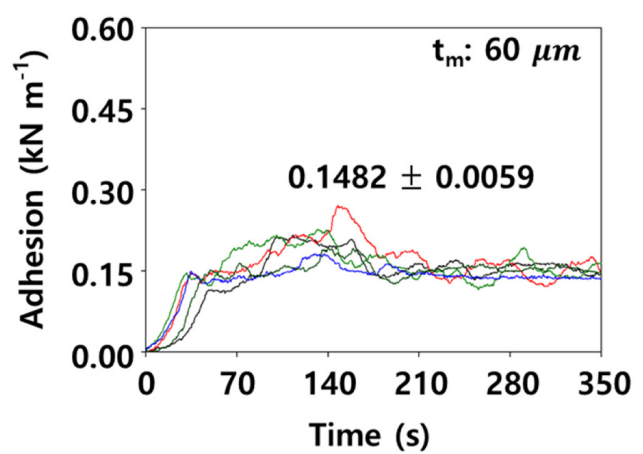

B

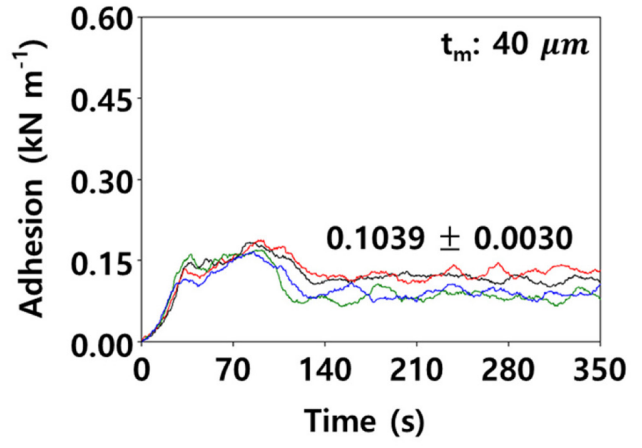

D

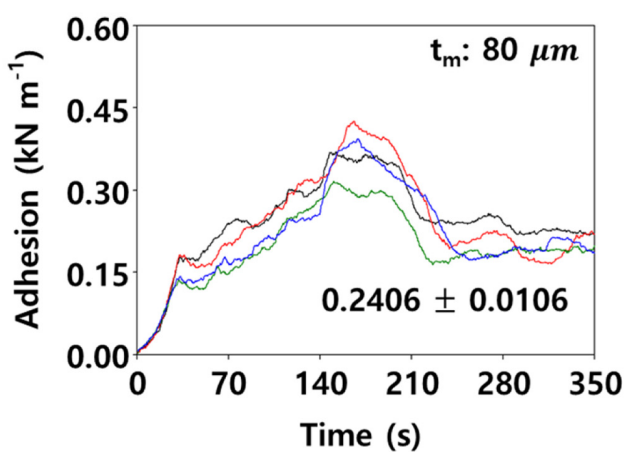

Fig. 1. Adhesion profiles of the standard electrode sample at the depths of A) $20 \mu \mathrm{m}, \mathrm{B}) 40 \mu \mathrm{m}, \mathrm{C}) 60 \mu \mathrm{m}$, and D) $80 \mu \mathrm{m}$ based on the conventional method (Measurements at each depth were repeated four times).

at each depth looked quite similar, which supports the accuracy of the SAICAS measurement (Fig. 1). From these results, assuming that the adhesion is proportional to the binder content, it can be reasonably estimated that the binder content increased as the depth increased. However, when the same standard electrode was analyzed by LIBS (Fig. S1), the binder content at the depths of $20 \mu \mathrm{m}, 40 \mu \mathrm{m}, 60 \mu \mathrm{m}$, and $80 \mu \mathrm{m}$ was found to be similar. This inconsistency should be tackled by reconsidering the factors that have been obscured or ignored in composite electrodes with low thickness or loading density $[27,31,39,41,45,46]$.

\subsection{Designing a new measurement strategy}

One of these factors is the frictions at the front and side of the blade, which are caused by the weight of the cut parts of the composite electrode and the contact between the moving blade and the side of the sample, respectively (Scheme 2A). Another factor that was never considered in previous works is the additional force required to cut both side-areas of the sample and the increase in the applied force due to the augmented actual peeling area at the front of the blade, as shown in Scheme 2B.

Thus, without proving that all other factors are negligible, the adhesion converted from the measured horizontal force $\mathrm{F}_{\mathrm{h}}$ cannot represent the corresponding physical property. In particular, the general understanding supported by higher adhesion, observed with increased cutting depth in previous works, should be reevaluated by fabricating control electrode samples and analyzing them under different conditions.

3.3.1 Friction at the front of the blade caused by the weight of cut parts

One of these factors is the frictions at the front and side of the blade, which are caused by the weight of the cut parts of the composite electrode and the contact between the moving blade and the side of the 
A
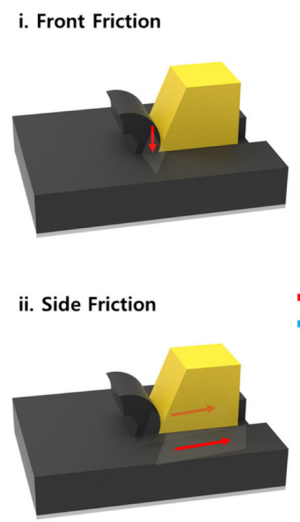

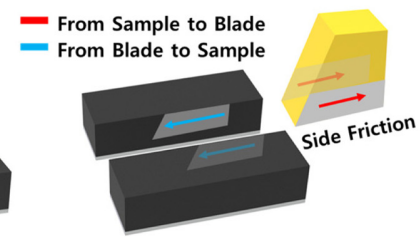

B

iii. Side Cutting

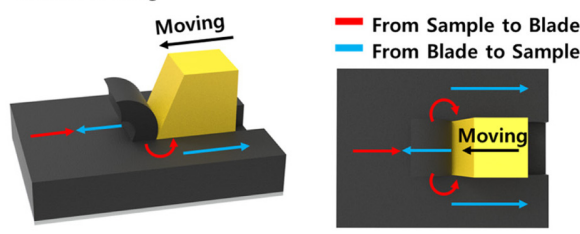

iv. Actual Peeling Area
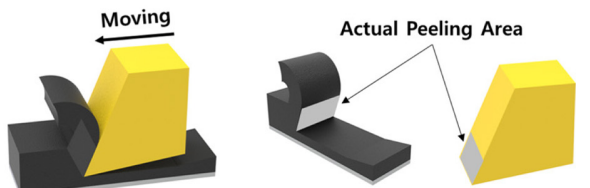

Scheme 2. Four overlooked factors caused by A) two frictions and B) the side-cutting and actual peeling area affecting the measured horizontal force $\mathrm{F}_{\mathrm{h}}$ with changes in the cutting depth.

sample, respectively (Scheme 2A). During the SAICAS measurement, the cut parts were pushed up from the sample and pressed down the front of the blade by their mass, which generated friction(i in Scheme 2A). The mass of cut parts (also called chips) can be calculated by multiplying the areal mass $\left(\mathrm{m}_{\mathrm{A}}\right.$, $\left.\mathrm{mg} \mathrm{cm}{ }^{-2}\right)$, cut area $\left(\mathrm{b} \times \Delta \mathrm{x}, \mathrm{cm}^{2}\right)$, and relative depth ratio $\left(t_{m} / t\right)$. Thus, the weight of the cut parts applied to the blade was also estimated during the measurement period. However, regardless of the amount of cut parts that accumulated during measurement, their weight did not exceed $10^{-6} \mathrm{~N}$, which is negligibly low compared with the measured total peel force of approximately $0 . x \mathrm{~N}$ (Fig. S4). Thus, despite the significant increase in the cutting thickness, its contribution to the total peel force is negligible.

\subsubsection{Friction on the side of the blade}

Cutting remains, such as a burr, can also cause friction at the side of the blade(ii in Scheme 2A). To measure this friction, an electrode sample was prepared using the following procedure: the electrode was cut once at $60 \mu \mathrm{m}$ for $350 \mathrm{~s}$, and the blade was returned to the starting point. Then, the force, which is related to the friction between the blade and sides of the sample, was measured again (Fig. S5). The maximum and average values were $0.0170 \mathrm{~N}$ and $0.0119 \mathrm{~N}$, respectively. This level of strength is similar to the magnitude of error caused by general atmospheric vibrations and wind. Thus, this side frictional force is also negligible despite the significant increase in the cutting depth.
3.3.3 Additional peel force on the side of the blade

When measuring adhesion by depth, only the force applied to the bottom of the blade should be quantified. But the blade cuts the sides as well as bottom, which adds extra force (iii in Scheme 2B). Also, as the blade cuts the sample, the sample is subjected to a force in the direction of movement at the front of the blade and in the opposite direction at the side of the blade. It causes moments that push the sides of the blade and the force is applied to the measured adhesion.

Nevertheless, the peel force on the side of the blade has never been seriously considered because the cutting depth is often tens of micrometers, which is approximately one hundredth of the blade width of $1 \mathrm{~mm}(1,000 \mu \mathrm{m})$. However, when the cutting depth increases beyond a critical point, the peel force acting on the side of the blade also increases to a point where it can no longer be ignored. Because the force for side cutting is quite high because the side of the blade is not sharp. The images of electrode surface obtained by confocal optical microscope and scanning electron microscopy supports that a large force is applied at the side (Fig. S2). the particles were peeled off from the composite electrode by the side of the blade and cut by the bottom of the blade (Fig. $\mathrm{S} 2 \mathrm{~B})$.

To better understand the force required for the side of the blade, we developed a stress evaluation model, which adopted the measurement condition described in Scheme 1 to simulate the stress distribution on the 
A

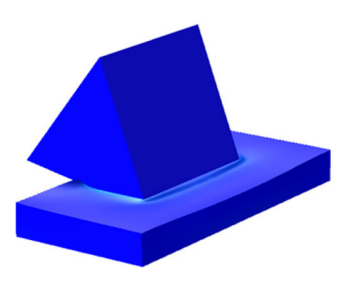

B

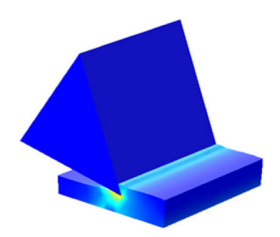

Normal Stress

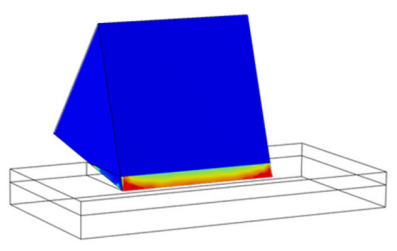

Normal Stress

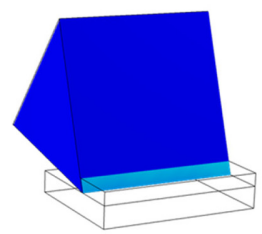

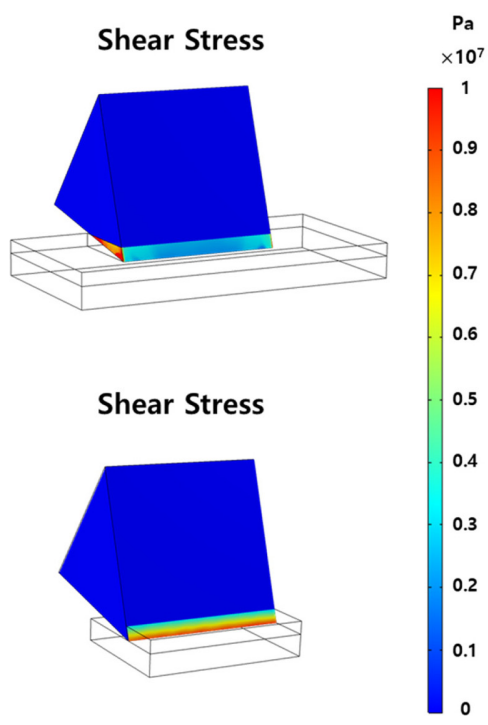

Fig. 2. 3D stress distribution simulation during SAICAS measurement with A) the original electrode sample (the thickness: $80 \mu \mathrm{m})$ and $\mathrm{B}$ ) the pretreated electrode sample having the same width as the blade.

blade during SAICAS measurement. For this model, three (3) main Parameters, Young's modulus (199 GPa), Poisson's ratio (0.25) and density (2.6 g $\left.\mathrm{cm}^{-3}\right)$ are used and the normal stress and shear stress were simulated after $0.01 \mathrm{~s}$. Using this model, we compared the stress distribution on the blade to determine whether it should cut the side of the sample. As shown in Fig. 2, not only a larger normal stress was generated at the edge of the front of the blade and considerable shear stress formed the side of the blade because of the moment created in the sample when the side of the sample exists. Whereas, in the pretreated sample, which was precut to the same width as the blade, even normal stress was shown on the front of the blade and no shear stress was observed on the side of the blade. Thus, a considerable portion of the horizontal peel force is responsible for this sidecutting.

To confirm the above simulation result, the pretreated sample shown in Fig. 2B was prepared using the procedure described in Fig. 3A. Both sides of the original sample were preliminary removed, leaving a composite layer of $1 \mathrm{~mm}$ width (i and ii in Fig. 3A). Thus, we could quantify the additional adhesion required to cut the side of the sample during the measurement (Fig. 3B and C). Although the difference in adhesion increased with increasing depth, the reduction ratios between the original and pretreated sam- ples converged to approximately $20 \%$ (except for $20 \mu \mathrm{m}$, Details in Table S1). That is, as reported in previous studies, when the measurement depth is below $20 \mu \mathrm{m}$, this side effect can be ignored $[27,31,39,41,45,46]$. However, when the cutting depth increases significantly, the pretreatment step, i.e., removing both sides of the sample, must be performed before the measurement to obtain the accurate adhesion of the sample.

\subsubsection{The effect of the actual peeling area}

As shown in Scheme 2B and stress simulation in Fig. 2, the stress applied to the front of the blade is not restricted to the line where the edge of the blade meets the line of the sample to be peeled. Thus, depending on the actual peeling area, additional force should be applied to the blade to reach the rupture stress of the sample. When the PVdF binder distribution was analyzed experimentally with the LIBS tool (Fig. S1), the trend did not match that of the adhesion depicted in Fig. 3C. There are no other methods available to investigate the effect of the peeling area on the adhesion with controlled samples, and it is almost impossible to determine or control the actual peeling area during measurement. Thus, we fabricated more advanced control samples without sides and the same remaining thickness to cut as schematically illustrated in Fig. 4A. For instance, when the 
A

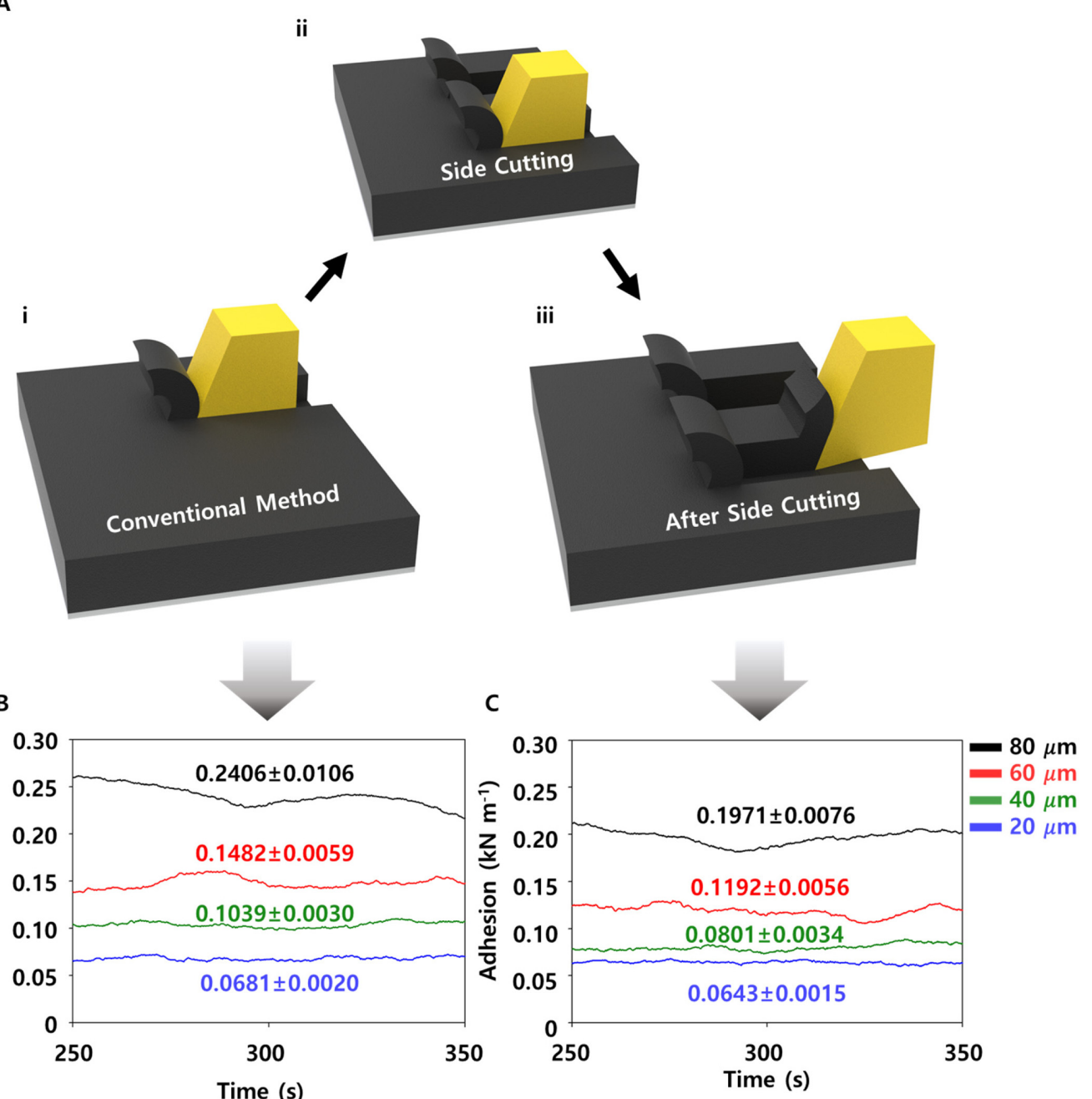

Fig. 3. A) A pretreatment procedure to remove both sides of the sample and the adhesion profiles of B) the original sample and C) pretreated sample.

adhesion was measured at a depth of $40 \mu \mathrm{m}$, the original sample was precut to remove both sides (i and ii in Fig. 4). Then, the $20 \mu \mathrm{m}$ thick sample was cut again to retain only a $20 \mu \mathrm{m}$ electrode coating layer (iii in Fig. 4). Similarly, to measure the adhesion at a depth of $80 \mu \mathrm{m}$ with the same actual peeling area, the same pretreatment and $60 \mu \mathrm{m}$ precutting steps were taken, followed by the SAICAS measurement.

The adhesion at $40 \mu \mathrm{m}$ and $80 \mu \mathrm{m}$ were measured as $0.0554 \mathrm{kN} \mathrm{m}^{-1}$ (Reduction ratio: $30.84 \%$ ) and $0.0631 \mathrm{kN} \mathrm{m}^{-1}$ (Reduction ratio: $67.99 \%$ ), respectively (Fig. 4B and C, and Table S2), which is similar to the trend of the binder distribution in Fig. S1. In other words, compared with the adhesion of $0.0643 \mathrm{kN} \mathrm{m}^{-1}$ at $20 \mu \mathrm{m}$ after side pretreatment, preliminary cutting both sides (Fig. 3C), the higher adhesions at $40 \mu \mathrm{m}$ and $80 \mu \mathrm{m}$ can be attributed to the additional $20 \mu \mathrm{m}$ and $60 \mu \mathrm{m}$ electrode layers. This result indicates that the actual peeling area significantly affects the adhesion. When the adhesions at different depths were compared to investigate the cohesive or adhesive properties of the sample, the precut step was required to minimize the contribution of the enlarged peeling area. To compare the adhesions related to the cohesive and adhesive properties, thus, both side pretreatment and top-layer precutting 
A
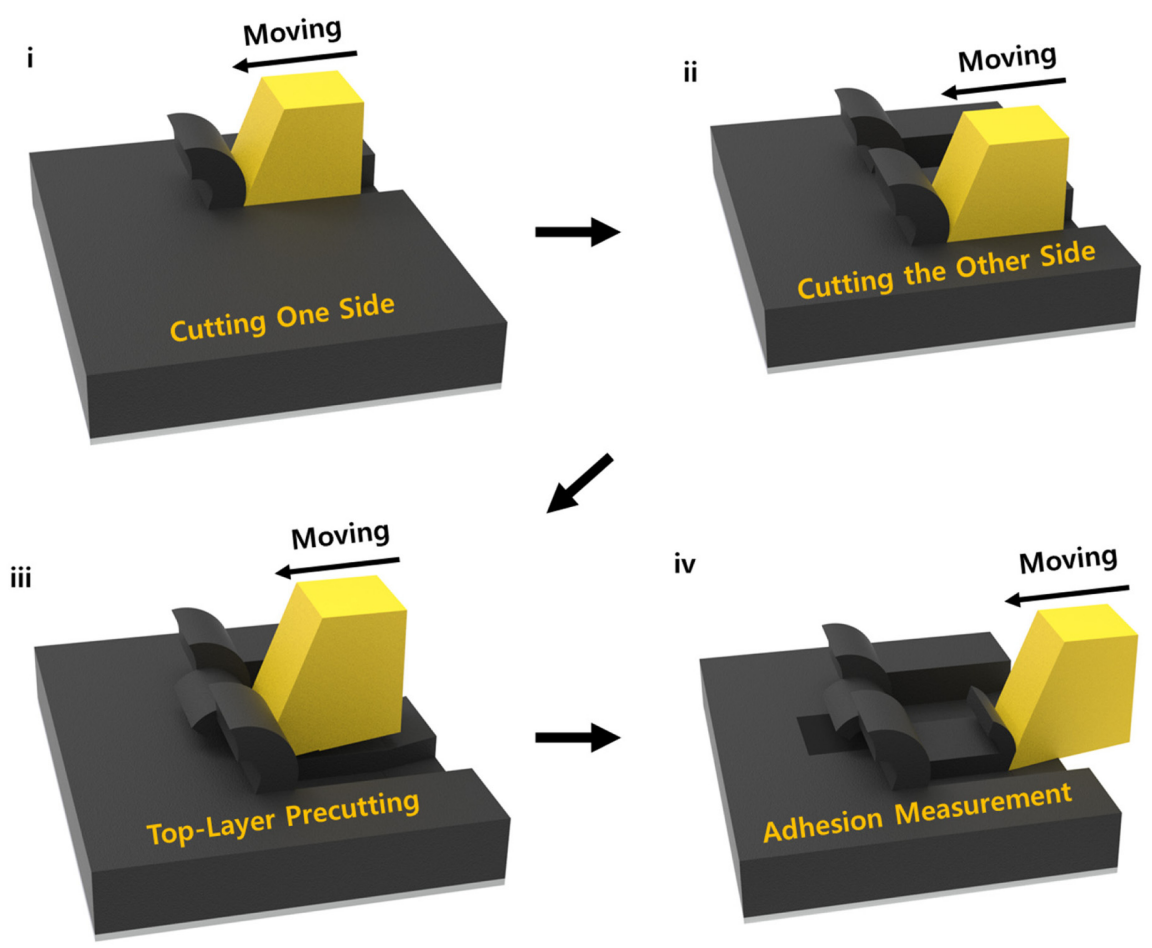

B

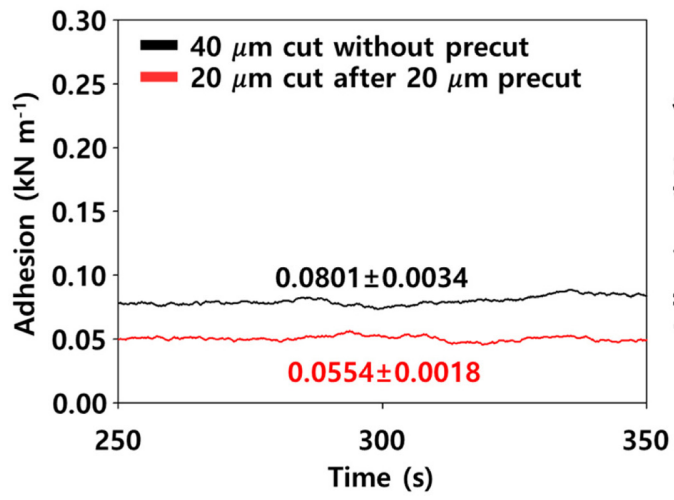

C

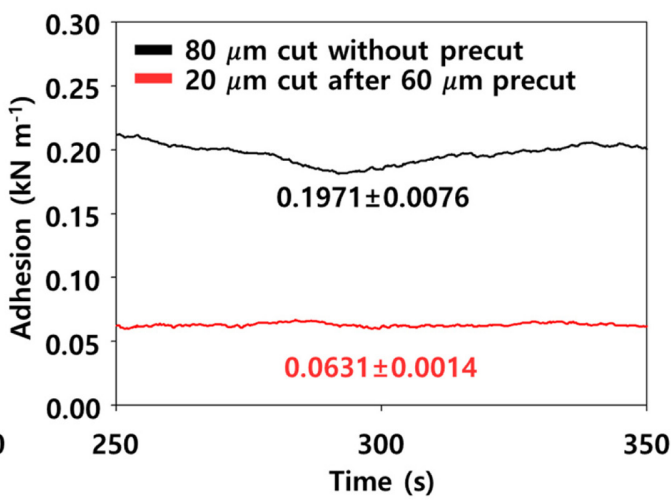

Fig. 4. A) Schematic of the side pretreatment and top-layer precutting procedures in which the side to be cut and the specific thickness of the sample have a similar actual peeling area. The adhesion profiles of the samples measured at B) $40 \mu \mathrm{m}$ after $20 \mu \mathrm{m}$ precutting and without precutting, and C) $80 \mu \mathrm{m}$ depth after $60 \mu \mathrm{m}$ precutting and without precutting.

are strongly recommended before SACIAS measurement. Comparing the adhesions of some samples is acceptable when their design parameters and measurement conditions are the same. Specifically, when studying the adhesive strengths of two different binders without pretreatment and precutting, all the adhesions can be used, in which the binder is more adhesive in the brittle composite electrode. There- fore, an optimal method should be selected according to the characteristics of the sample and the purpose of SAICAS measurement.

\section{Conclusions}

Thanks to the convenience of using microblade cutting methods through a device called SAICAS, the 
adhesive or cohesive strength of composite electrodes is readily measured by dividing the horizontal peel force by the blade width without deep consideration. However, this work proved that the peel force is not only dependent on the adhesive or cohesive strength, but also affected by other factors, particularly in the thick electrode composite layer: 1) the friction at the front blade caused by the cut parts; 2) the friction on the side of the blade; 3 ) the force to cut both sides of the sample; and 4) the additional force proportional to the increase in the actual peeling area. With well-designed control samples (side pretreated or top-layer precut), we proved that the first two factors are negligible despite the significant increase in the cutting depth. The last two factors are mainly responsible for the increase in peel forces with the increase in the cutting depth. As demonstrated in a case study, the adhesion of the original composite electrode at $80 \mu \mathrm{m}$ was approximately $0.2406 \mathrm{kN} \mathrm{m}^{-1}$, which is four times higher than that at $20 \mu \mathrm{m}$. However, when the sample was pretreated and precut, that is, the side and the specific thickness of the sample were cut in advance, the adhesion became similar to that at $20 \mu \mathrm{m}$ due to removal of last two factors mentioned above.

In conclusion, based on our recommended method, binder distribution determines the adhesion of the composite electrode. However, with the conventional method, cutting depth leads to significant effect to measured adhesion owing to required additional forces for side cutting and enlarged actual peeling area. Therefore, to determine the adhesion associated with the adhesive or cohesive strength of the composite electrode at a specific depth, conducting both pretreatment and precutting is highly recommended as a new standard analytical method.

\section{Acknowledgements}

This work was supported by an Electronics and Telecommunications Research Institute (ETRI) grant funded by the Korean government [21ZB1200, Development of ICT Materials, Components, and Equipment Technologies], the National Research Foundation of Korea (NRF) grant funded by the Korea government (MSIT) (No. 2020R1A4A4079810) and the grant from R\&D Program of the Korea Railroad Research Institute (KRRI), Republic of Korea. We are also very grateful for the support from the DGIST Supercomputing and Bigdata Center.

\section{Supporting Information}

Supporting Information is available at https:// doi.org/10.33961/jecst.2021.00976

\section{References}

[1] T. Mochizuki, S. Aoki, T. Horiba, M. S. Dobrick, Z. J. Han, S. Fukuyama, H. Oji, S. Yasuno, S. Komaba, $A C S$ Sustainable Chem. Eng., 2017, 5(7), 6343-6355.

[2] M. Ling, J. Qiu, S. Li, C. Yan, M. J. Kiefel, G. Liu, S. Zhang, Nano Lett., 2015, 15(7), 4440-4447.

[3] L. Ma, J. Meng, Y. Pan, Y. J. Cheng, Q. Ji, X. Zuo, X. Wang, J. Zhu, Y. Xia, Langmuir, 2020, 36(8), 20032011.

[4] D. W. Choi, K. L. Choy, Mater. Des., 2020, 191, 108669.

[5] S. Gao, F. S, A. Brady, Y. Pan, A. Erwin, D. Yang, V. Tsukruk, A. G. Stack, T. Saito, H. Yang, P. F. Cao, Nano Energy, 2020, 73, 104804.

[6] M. Zheng, X. Cai, Y. Tan, W. Wang, D. Wang, H. Fei, P. Saha, G. Wang, Chem. Eng. J., 2020, 389, 124404.

[7] Q. H. Nguyen, J. S. Choi, Y. C. Lee, I. T. Kim, J. Hur, J. Ind. Eng. Chem., 2019, 69, 116-126.

[8] S. Y. Lee, Y. Choi, S. H. Kwon, J. S. Bae, E. D. Jeong, J. Ind. Eng. Chem., 2019, 74, 216-222.

[9] M. Müller, L. Pfaffmann, S. Jaiser, M. Baunach, V.Trouillet, F. Scheiba, P. Scharfer, W. Schabel, W. Bauer, J. Power Sources, 2017, 340, 1-5.

[10] Y. Su, K. Zhou, Y. Yuan, W. Liu, Y. Deng, IOP Conf. Ser.: Mater. Sci. Eng., 2020, 793(1), 012025.

[11] J. Landesfeind, A. Eldiven, H. A. Gasteiger, $J$. Electrochem. Soc., 2018, 165(5), A1122.

[12] P. Harte, M. Evertz, T. Schwieter, M. Diehl, M. Winter, S. Nowak, Anal. Bioanal. Chem. 2019, 411(3), 581-589.

[13] A. Danczak, L. Klemettinen, M. Kurhila, P. Taskinen, D. Lindberg, A. Jokilaaksom, Batteries, 2020, 6(1), 16.

[14] T. Tirronen, D. Sukhomlinov, H. O'Brien, P. Taskinen, M. Lundstrom, J. Cleaner Prod., 2017, 168, 399-409.

[15] T. Schwieters, M. Evertz, M. Mense, M. Winter,S. Nowak, J. Power Sources, 2017, 356, 47-55.

[16] S. F. Durrant, J. Anal. At. Spectrom., 1999, 14(9), 13851403.

[17] D. Günther, S. E. Jackson and H. P. Longerich, Spectrochim Acta Part B At Spectrosc, 1999, 54(3-4), 381-409.

[18] J. A. C. Broekaert, J. Anal. Chem., 2000, 368(1), 15-22.

[19] K. Niemax, Fresenius J. Anal. Chem., 2001, 370(4), 332-340.

[20] R. E. Russo, X. Mao, H. Liu, J. Gonzalez, S. S. Mao, Talanta, 2002, 57(3), 425-451

[21] D. Günther, I. Horn and B. Hattendorf, Fresenius J Anal Chem, 2000, 368(1), 4-14.

[22] J. S. Becker, J. Anal. At. Spectrom., 2002, 17(9), 11721185. 
[23] J. S. Becker, Spectrochim. Acta B, 2002, 57(12), 18051820.

[24] W. K. Asbeck, The measurement of adhesion in absolute units by knife-cutting methods: the hesiometer, presented at The Eleventh FATIPEC Congress, Brussels Congress Book, 1972, 78-87.

[25] 西山逸雄，高橋健造，色材協会誌，1989，62(12)，744748.

[26] J. Choi, M. H. Ryou, B. Son, J. Song, J. K. Park, K. Y. Cho, Y. M. Lee, J. Power Sources, 2014, 252, 138-143.

[27] B. Son, M. H. Ryou, J. Choi, T. Lee, H. Kyun Yu, J. H. Kim, Y. M. Lee, A.C.S. Appl. Mater. Interfaces, 2014, 6(1), 526-531.

[28] D. Song, S. H. Lee, K. Kim, M. H. Ryou, W. H. Park, Y. M. Lee, Appl. Chem. Eng., 2015, 26(6), 674-680.

[29] J. Choi, K. Kim, J. Jeong, K. Y. Cho, M. H. Ryou, Y. M. Lee, A.C.S. Appl. Mater. Interfaces, 2015, 7(27), 1485114858.

[30] I. Cho, S. Gong, D Song, Y. G. Lee, M. H. Ryou, Y. M. Lee, Sci. Rep., 2016, 6(1), 1-9.

[31] K. Kim, S. Byun, I. Cho, M. H. Ryou, Y. M. Lee, A.C.S. Appl. Mater. Interfaces, 2016, 8(36), 23688-23695.

[32] H. Jeon, S. Y. Jin, W. H. Park, H. Lee, H. T. Kim, M. H. Ryou and Y. M. Lee, Electrochim. Acta, 2016, 212, 649656.

[33] S. W. Kim, M. H. Ryou, Y. M. Lee, K. Y. Cho, J. Alloys Compd., 2016, 675, 341-347.

[34] J. Oh, D. Jin, K. Kim, D. Song, Y. M. Lee, M. H. Ryou, A.C.S. Omega, 2017, 2(11), 8438-8444.

[35] H. Jeon, J. Choi, M. H. Ryou, Y. M. Lee, A.C.S. Omega,
2017, 2(5), 2159-2164.

[36] H. Jeon, I. Cho, H. Jo, K. Kim, M. H. Ryou, Y. M. Lee, Rsc Adv., 2017, 7(57), 35681-35686.

[37] M. Latifatu, C. Y. Bon, K. S. Lee, L. Hamenu, Y. I. Kim, Y. J. Lee, Y. M. Lee, J. M. Ko, J. Electrochem. Sci. Technol., 2018, 9(4), 330-338.

[38] H. Lee, H. K. Jeon, S. Gong, M. H. Ryou, Y. M. Lee, Appl. Surf. Sci., 2018, 427, 139-146.

[39] Y. Roh, S. Byun, M. H. Ryou, Y. M. Lee, J. Korean Electrochem. Soc., 2018, 21(3), 47-54.

[40] S. Byun, Y. Roh, D. Jin, M. H. Ryou, Y. M Lee, J. Korean Electrochem. Soc., 2018, 21(2), 28-38.

[41] K. Kim, S. Byun, J. Choi, S. Hong, M. H. Ryou, Y. M. Lee, ChemPhysChem., 2018, 19(13), 1627-1634.

[42] S. Byun, J. Choi, Y. Roh, D. Song, M. H. Ryou,Y. M. Lee, Electrochim. Acta, 2020, 332, 135471.

[43] J. Kim, S. Byun, S. Lee, J. Ryu, S. Cho, C. Oh, H. Kim, K. No, S. Ryu, Y. M. Lee, S. Hong, Nano Energy, 2020, $75,104992$.

[44] D. Jin, H. S. Bae, J. Hong, S. Kim, J. Oh, K. Kim, T. Jo, Y. M. Lee, Y. G. Lee, M. H. Ryou, Electrochim. Acta, 2020, 364, 136878.

[45] S. Byun, Y. Roh, K. M. Kim, M. H Ryou, Y. M. Lee, Appl. Mater. Today, 2020, 21, 100809.

[46] S. Byun, J-H Yu, J. Choi, S. Yun, Y. Roh, C. B. Dzakpasu, S. H. Park, J. G. Oh, B. K. Hong, Y. M. Lee, J. Power Sources, 2020, 455, 227928.

[47] D. Jin, Y. Roh, T. Jo, D. O. Shin, J. Song, J. Y. Kim, Y. G. Lee, H. Lee, M. H. Ryou, Y. M. Lee, Chem. Eng. J., 2021, 406, 126834. 